\title{
Pre-Treatment with Curcumin Ameliorates Cisplatin-Induced Kidney Damage by Suppressing Kidney Inflammation and Apoptosis in Rats
}

\author{
Authors \\ Vivian Soetikno, Shinta Dewi Permata Sari, Lulu UI Maknun, Nielda Kezia Sumbung, Deliana Nur Ihsani Rahmi, \\ Bashar Adi Wahyu Pandhita, Melva Louisa, Ari Estuningtyas
}

\author{
Affiliation \\ Department of Pharmacology and Therapeutic, Faculty of \\ Medicine, University of Indonesia, Jakarta, Indonesia \\ Key words \\ apoptosis, inflammation, renal pharmacology \\ received 13.04 .2018 \\ accepted 06.06.2018 \\ Bibliography \\ DOI https://doi.org/10.1055/a-0641-5148 \\ Published online: 26.6.2018 \\ Drug Res 2019; 69: 75-82 \\ (c) Georg Thieme Verlag KG Stuttgart · New York \\ ISSN 2194-9379 \\ Correspondence \\ Vivian Soetikno, MD, PhD \\ Department of Pharmacology and Therapeutic \\ Faculty of Medicine \\ University of Indonesia \\ Salemba Raya No. 6 \\ 10430 Jakarta \\ Indonesia \\ Tel.: +62/21/31930 481 \\ vivian_09st@yahoo.com
}

\section{ABSTRACT}

Objective In addition to oxidative stress, inflammation and apoptosis have an important role in the pathogenesis of cisplatin-induced kidney damage. This study aimed to investigate the molecular mechanisms of protective effects of curcumin against cisplatin-induced kidney inflammation and apoptosis in rats.

Materials and Methods Eighteen rats were equally divided into three groups; normal (0.5\% CMC-Na), cisplatin (CDPP) ( $7 \mathrm{mg} / \mathrm{kg}$ i.p.), and cisplatin + curcumin (CMN100) groups. Curcumin was given at a dose of $100 \mathrm{mg} / \mathrm{kg}$ orally for nine days, starts one week before giving a single dose of cisplatin. Kidney and plasma were taken for analysis.

Results Cisplatin challenged rats demonstrated kidney injury as shown by reduced creatinine clearance, increased of plasma BUN, plasma creatinine, and kidney MDA, decreased of kidney GSH levels, and kidney histopathology alterations. Also, cisplatin increased ERK1/2 phosphorylation and NF-KB expression, which subsequently increased mRNA expression of TNF- $\alpha$, IL-6, $\mathrm{KIM}-1$, NGAL, and Bax/Bcl-2 ratio as well as decreased mRNA expression of IL-10 in kidney tissues. Pre-treatment with curcumin significantly ameliorated inflammation and apoptosis induced by cisplatin. In addition, curcumin downregulated Ctr1 and OCT2 drug transporters as compared to cisplatin group. Histopathological examination furthers confirmed the kidney damage protection effect of curcumin.

Conclusions These data indicate that curcumin has nephroprotective properties against cisplatin-induced kidney damage in rats and this effect is associated with its anti-inflammatory and anti-apoptosis profiles, in addition to its antioxidant. Hence, curcumin may be useful for preventing kidney damage against cisplatin administration.

\section{Introduction}

Cisplatin has been used as a standard agent of combination chemotherapy in several cancers, such as nasopharyngeal, lung, and ovarian cancer. However, it has many severe side effects that limit the therapeutic use of cisplatin, one of them is kidney damage $[1,2]$. Over the last few decades, it has been studied that the mechanisms of cisplatin-induced kidney damage are complex and involved numerous cellular and molecular processes including in- flammation, apoptosis, accumulation of cisplatin in renal tubular cells via renal drug transporters, $\mathrm{Ctr} 1$ and $\mathrm{OCT} 2$, and involvement of mitogen-activated protein kinases (MAPK) pathways [3, 4]. In particular, extracellular-regulated kinase (ERK) $1 / 2$, one of the MAPK pathway is considered as an important mediator of signal transduction processes, namely cell survival, cell division, gene expression, and cell metabolism that plays role in injury, death, and inflammation of kidney tubular cells due to cisplatin administration 
[5]. Even though various treatment strategies namely saline hydration and diuresis have been suggested for prevention of cisplatininduced kidney damage, but its prevalence is still high. In fact, the prevalence of cisplatin-induced kidney damage was 34\% after fourth cycles and $52 \%$ after six cycles of cisplatin chemotherapy in adult cancer patients treated with cisplatin at a dose of $\geq 60 \mathrm{mg} /$ $\mathrm{m}^{2}$ at Dharmais National Cancer Hospital, Jakarta, Indonesia [6].

An active nature product of Asian herb medicine, curcumin, shows many protective effects, including against inflammatory and oxidative stress conditions. Previous studies have demonstrated that curcumin at a dose of $100 \mathrm{mg} / \mathrm{kg}$ orally in mice and $60 \mathrm{mg} / \mathrm{kg}$ in rats reduced concentration of tumor necrosis factor (TNF)- $\alpha$ and inhibited oxidative stress in cisplatin-induced nephrotoxicity [7, 8]. Moreover, Topcu-Tarladacalisir et al. [9] reported curcumin administration provided protection against cisplatin-induced renal tubular cell apoptosis. However, the molecular mechanisms behind the anti-inflammatory and anti-apoptotic effects of curcumin in the cisplatin-induced kidney damage have not been explored.

Therefore, in this study, we aimed to investigate the possible molecular mechanisms of anti-inflammatory and anti-apoptotic effects of curcumin in cisplatin-induced kidney damage.

\section{Materials and Methods}

\section{Chemicals and drugs}

Curcumin was purchased from Xi'an Pincredit Bio-Tech Co., Ltd. (Shaanxi, China; Batch \#PI-Cl-150302). Cisplatin and carboxymethylcellulose sodium (CMC-Na) were purchased from Sigma Aldrich (St. Louis, MO, USA). Glutathione (GSH) and malondialdehyde (MDA) assay kits were purchased from AAT Bioquest, Co., USA. The urea and creatinine assay kits were obtained from DiaSys Diagnostic System GmbH (Holzheim, Germany). All reagents and chemicals used were of analytical grade.

\section{Experimental animals}

Eight week olds male Sprague-Dawley rats (200-250 g) were obtained from Indonesia National Agency of Drug and Food Control and were kept under standard conditions of temperature (26-28 C), humidity, and 12-h light/dark cycle. Animals were acclimatized for 7 days prior the experiment and allowed free access of food and water at all times. All animal procedures were conducted in accordance with the Guide for Care and Use of Laboratory Animals of our institute and approved by Animal Ethics Committee, University of Indonesia (Protocol no. 536/UN2.F1/ETIK/2016). All efforts were made to minimize sufferings.

\section{Experimental design}

The rats were divided at random into 3 groups of 6 animals each and treated for 9 days. The first group (Normal) was given the vehicle ( $0.5 \%$ CMC-Na) by gavage once daily and a single intraperitoneal (i.p.) injection of normal saline on the $7^{\text {th }}$ day of the study. The second group (CDPP) was given the vehicle by gavage once daily for 9 days starting 7 days before giving cisplatin ( $7 \mathrm{mg} / \mathrm{kg}$ i.p.) as a single dose to induce kidney damage [10]. The third group (CDPP + CMN100) was given curcumin at a dose of $100 \mathrm{mg} / \mathrm{kg}$ once daily by gavage for 9 days starting 7 days before giving a single dose of cisplatin (7 mg/kg i.p.). The dose of curcumin ( $100 \mathrm{mg} / \mathrm{kg}$ orally) was selected on the basis of previous study [7]. At the end of experiment, the animals were anesthetized with ether and euthanized by cervical dislocation. Blood samples were collected and plasma was separated to assess creatinine and BUN; kidney tissues were isolated and then stored at $-80^{\circ} \mathrm{C}$ for further analysis. Before sacrificed, individual rats were placed in metabolic cages to obtain $24 \mathrm{~h}$ urine collections for the measurement of urine creatinine determined by Jaffe method [11].

\section{Assessment of plasma biochemical parameters}

Renal function tests

Blood samples were collected via heart puncture in each animal at the time of sacrifice into EDTA vacutainer tubes. EDTA-blood was centrifuged at $3000 \mathrm{xg}, 4^{\circ} \mathrm{C}$, for $15 \mathrm{~min}$ for separation of plasma. The plasma was used for the estimation of creatinine and BUN. Levels of plasma urea was measured using urease-GLDH:UV enzymatic test according to DiaSys kit. BUN was determined by multiplying the result of serum urea by 0.467 . Plasma and urine creatinine were measured spectrophotometrically at a wavelength of $520 \mathrm{mu}$ according to the method described by Jaffe. Creatinine clearance was calculated in individual rats as follows: Creatinine clearance $=$ urine creatinine $x$ urine volume/plasma creatinine $x$ time [12].

\section{Lipid peroxidation}

Renal MDA content, product of lipid peroxidation, assessed by measuring the thiobarbituric acid (TBA) reactivity of MDA. For this purpose, kidney tissue was rinsed, weighed, and a total of $200 \mathrm{~mL}$ of sample was resuspended in $1800 \mathrm{~mL}$ of distilled water, added $1 \mathrm{~mL}$ of $20 \%$ of trichloroacetic acid (TCA) and $2 \mathrm{~mL}$ of $0.67 \%$ TBA, and heated at $100{ }^{\circ} \mathrm{C}$ for $10 \mathrm{~min}$. The mixtures, then, were centrifuged and the supernatant were collected. The absorbance was read at $530 \mathrm{~nm}$ wave-length.

\section{Measurement of antioxidant status}

Renal reduced GSH content was determined by a colorimetric using a diagnostic kit, Amplite Rapid Fluorimetric Glutathione GSH/GSSG ratio assay kit. The absorbance was read by a fluorescence microplate reader at $E_{x} / E_{m}=490 / 520 \mathrm{~nm}$.

\section{Quantitative real-time PCR assay}

The total RNA samples from kidney tissues of all rats were extracted using Macherey-Nagel RNA purification (Macherey-Nagel GmbH \& Co. KG, Germany) following the manufacturer's protocol. The isolated total RNA concentration and purity were measured spectrophotometrically at $260 \mathrm{~nm}$ wavelength using Nanodrop 2000 (Thermo Scientific, Waltham, MA). The samples with sufficient purity $\left(A_{260 / 280}>1.8\right)$ were subjected to the next experiment. cDNA was synthesized using an AffinityScript QPCR cDNA Synthesis Kit according to the manufacturer's instructions (Agilent Genomics, (A, USA). The resulted cDNA concentration and purity was measured spectrophotometrically at $260 \mathrm{~nm}$ using Nanodrop 2000. For Real-time PCR, FastStart Essential DNA Green Master (Roche, Jakarta, Indonesia) was used and subjected to quantitative PCR (qPCR) in a LightCycler Nano Roche ${ }^{T M}$. The sequences of primers were commercially synthesized and listed in $>$ Table 1 . Target genes were amplified using FastStart Essential DNA Green Master (Roche, 
- Table 1 Primer sequences used for RT-PCR (5' to $\left.3^{\prime}\right)$.

\begin{tabular}{|l|l|}
\hline Gene & Sequences \\
\hline$\beta$-actin & $\begin{array}{l}\text { Forward: GGCATCGTGATGGACTCCG } \\
\text { Reverse: GCTGGAAGGTGGACAGCGA }\end{array}$ \\
\hline Bcl-2 & $\begin{array}{l}\text { Forward: CTGGTGGACAACATCGCTCTG } \\
\text { Reverse: GGTCTGCTGACCTCACTTGTG }\end{array}$ \\
\hline Bax & $\begin{array}{l}\text { Forward: GCAAAGTAGAAGGCAACG } \\
\text { Reverse: GGCCAAGATCATCCATGACAACT }\end{array}$ \\
\hline TNF- $\alpha$ & $\begin{array}{l}\text { Forward: TCTACTACCAGGTTCTCTTCA } \\
\text { Reverse: CTCCTGGTATGAAATCGCAAATC }\end{array}$ \\
\hline IL-6 & $\begin{array}{l}\text { Forward: ACTTCCAATGCTCTCCTAATGG } \\
\text { Reverse: GTGCTTTCAAGATGAGTTGGATG }\end{array}$ \\
\hline Ctr1 10 & $\begin{array}{l}\text { Forward: CCCAGAAATCAAGGAGCATTTG } \\
\text { Reverse: GGAGAAATCGATGACAGCGT }\end{array}$ \\
\hline OCT2 & $\begin{array}{l}\text { Forward: CATGATGATGATGCCTATGACC } \\
\text { Reverse: CAGCATCTGCTGCCCAAC }\end{array}$ \\
\hline NGAL & $\begin{array}{l}\text { Forward: TCTTGATGTACAATTGGTTCACG } \\
\text { Reverse: AACCACAGCAAATACGACCAG }\end{array}$ \\
\hline KIM-1 & $\begin{array}{l}\text { Forward: GATGTTGTTATCCTTGAGGCCCC } \\
\text { Reverse: CACTGACTACGACCAGTTTGCC }\end{array}$ \\
\hline
\end{tabular}

Jakarta, Indonesia). Amplification was performed in 45 cycles followed by melting curve analysis. The condition of amplification of each gene were as follows: $\beta$-actin (denaturation: $95^{\circ} \mathrm{C}, 20 \mathrm{~s}$; annealing: $60^{\circ} \mathrm{C}, 20 \mathrm{~s}$; elongation: $72^{\circ} \mathrm{C}, 1 \mathrm{~s}$ ), $\mathrm{Bcl}-2$ (denaturation: $95^{\circ} \mathrm{C}, 20 \mathrm{~s}$; annealing: $57^{\circ} \mathrm{C}, 20 \mathrm{~s}$; elongation: $72^{\circ} \mathrm{C}, 9 \mathrm{~s}$ ), Bax (denaturation: $95^{\circ} \mathrm{C}, 20 \mathrm{~s}$; annealing: $57^{\circ} \mathrm{C}, 20 \mathrm{~s}$; elongation: $72^{\circ} \mathrm{C}$, $9 \mathrm{~s}$ ), IL-6 (denaturation: $95^{\circ} \mathrm{C}, 20 \mathrm{~s}$; annealing: $57^{\circ} \mathrm{C}, 20 \mathrm{~s}$; elongation: $72^{\circ} \mathrm{C}, 9 \mathrm{~s}$ ), IL-10 (denaturation: $95^{\circ} \mathrm{C}, 20 \mathrm{~s}$; annealing: $57^{\circ} \mathrm{C}$, $20 \mathrm{~s}$; elongation: $72^{\circ} \mathrm{C}, 9 \mathrm{~s}$ ), TNF- $\alpha$ (denaturation: $95^{\circ} \mathrm{C}, 10 \mathrm{~s}$; annealing: $60^{\circ} \mathrm{C}, 30 \mathrm{~s}$; elongation: $72^{\circ} \mathrm{C}, 1 \mathrm{~s}$ ), kidney injury molecule (KIM)- 1 (denaturation: $95^{\circ} \mathrm{C}, 10 \mathrm{~s}$; annealing: $60^{\circ} \mathrm{C}, 20 \mathrm{~s}$; elongation: $72^{\circ} \mathrm{C}, 1 \mathrm{~s}$ ), neutrophil gelatinase associated lipocalin (NGAL) (denaturation: $95^{\circ} \mathrm{C}, 10 \mathrm{~s}$; annealing: $60^{\circ} \mathrm{C}, 10 \mathrm{~s}$; elongation: $72^{\circ} \mathrm{C}$, $1 \mathrm{~s}), \mathrm{Ctr} 1$ (denaturation: $95^{\circ} \mathrm{C}, 10 \mathrm{~s}$; annealing: $60^{\circ} \mathrm{C}, 10 \mathrm{~s}$; elongation: $72^{\circ} \mathrm{C}, 1 \mathrm{~s}$ ), OCT2 (denaturation: $95^{\circ} \mathrm{C}, 10 \mathrm{~s}$; annealing: $60^{\circ} \mathrm{C}$, $10 \mathrm{~s}$; elongation: $\left.72^{\circ} \mathrm{C}, 1 \mathrm{~s}\right)$. Level of mRNA expression was quantified based on $2^{-\triangle \Delta C T}[13]$.

\section{Western blotting assay}

The $100 \mathrm{mg}$ of frozen kidney tissues were homogenized in an icecold buffer (50 mM Triz-HCL, pH 7.4; 200 mM NaCl; 20 mM NaF; $1 \mathrm{mM} \mathrm{Na} \mathrm{VO}_{4} ; 1 \mathrm{mM}$ 2-mercaptoethanol; $0.01 \mathrm{mg} / \mathrm{mL}$ leupeptin; $0.01 \mathrm{mg} / \mathrm{mL}$ aprotinin). Homogenates were centrifuged at $3000 \mathrm{x}$ $\mathrm{g}, 10 \mathrm{~min}, 4^{\circ} \mathrm{C}$ and the supernatant were collected and stored at $-80^{\circ} \mathrm{C}$ until analysis. The total protein concentrations in sample were measured using BCA Protein Assay Kit (Thermo Fisher Scientific, USA). Aliquots of supernatants containing equal amounts of protein $(70 \mu \mathrm{g})$ were separated by SDS-PAGE $(10 \%)$, transferred onto nitrocellulose membranes, then blocked and incubated overnight at $4{ }^{\circ} \mathrm{C}$ with primary antibodies as follows phospho-ERK $1 / 2$ (Cell Signaling-9106) normalized by the basal level of ERK1/2 (Cell Signaling-9102), and NF-KB (Cell Signaling-4717) normalized by $\beta$-actin protein expression in the same sample. All primary antibod- ies were used at a dilution of 1:1000 and secondary antibodies were used at a dilution of 1:5000. Protein bands were visualized by the enhanced chemiluminescence $(\mathrm{ECL})$ method.

\section{Histopathological assay}

The kidney tissue was cut into about 2-mm thick transverse slices, fixed in $10 \%$ formalin. After being embedded in paraffin, the transverse sections were stained with hematoxylin-eosin ( $\mathrm{H} \& \mathrm{E})$ for histological evaluation. The scoring for necrotic lesion in the proximal tubules was described as follows: 0 indicates no necrosis; 1 indicates a few necrotic lesions; 2 indicates $50 \%$ necrosis lesions; 3 indicates $60 \%$ necrotic lesions; and 4 indicates necrotic lesions in almost all area [14].

\section{Statistical analysis}

The results are shown as mean \pm standard deviation (SD) and were analyzed by one-way ANOVA, followed by Tukey's methods for posthoc analysis. Comparisons between two groups were performed using an unpaired Student's t-test. Values of $\mathrm{p}<0.05$ indicate statistical significance. For statistical analysis, IBM SPSS software was used.

\section{Results}

\section{Effect of curcumin plasma creatinine, plasma BUN, and creatinine clearance}

To evaluate the effect of curcumin on preventing kidney dysfunction induced by cisplatin, we analyzed plasma creatinine, plasma BUN, and creatinine clearance ( $\triangleright$ Table 2 ). Cisplatin-treated group demonstrated a marked elevation of plasma creatinine and BUN by 2.4-fold and 5.7-fold, respectively, and a decreased of creatinine clearance by $60 \%$ as compared to that of normal group. On the other hand, pre-treatment with curcumin at a dose of $100 \mathrm{mg} / \mathrm{kg}$ significantly improved nephrotoxicity markers as shown by a significant reduction in plasma creatinine and BUN concentration by $33 \%$ and $56 \%$ when compared with cisplatin-treated group. Besides, creatinine clearance was significantly increased by 2 -fold when compared to the cisplatin-treated group.

\section{Effect of curcumin on lipid peroxidation and GSH content in kidney tissues}

Effects of curcumin and cisplatin on oxidative stress markers, such as MDA and GSH were shown in > Table 2. It was shown that cisplatin administration significantly increased MDA levels by 1.4 -fold and depleted antioxidant defenses, GSH levels by $12.7 \%$ as compared to that of normal group. Pre-treatment with curcumin protected against cisplatin-induced oxidative stress in kidney as indicated by lowering of MDA (13\%) and restoring of GSH levels to nearly basal levels observed in the normal group.

\section{Effect of curcumin on the expression of $p$-ERK $1 / 2$ in cisplatin-induced nephrotoxicity rats}

As shown in > Fig. 1a, cisplatin-treated group demonstrated significant increase of ERK1/2 phosphorylation by 2-fold as compared with those in the normal group. Whereas, curcumin at $100 \mathrm{mg} / \mathrm{kg}$ dose significantly decreased ERK $1 / 2$ phosphorylation by $35 \%$. 
- Table 2 Effect of curcumin on plasma creatinine, plasma BUN, Ccr, MDA level, and GSH activity.

\begin{tabular}{|c|c|c|c|}
\hline Variables & Normal $(n=6)$ & $\operatorname{CDDP}(n=6)$ & $\mathrm{CDDP}+\mathrm{CMN100}(\mathrm{n}=6)$ \\
\hline Plasma creatinine $(\mathrm{mg} / \mathrm{mL})$ & $0.59 \pm 0.08$ & $1.43 \pm 0.45^{*}$ & $0.96 \pm 0.24^{\#}$ \\
\hline Plasma BUN (mg/mL) & $16.51 \pm 3.8$ & $94.64 \pm 28.1^{*}$ & $41.81 \pm 10^{\#}$ \\
\hline $\mathrm{Ccr}(\mathrm{mL} / \mathrm{min})$ & $0.3 \pm 0.1$ & $0.12 \pm 0.07^{*}$ & $0.24 \pm 0.1^{\#}$ \\
\hline MDA (nmol/mg protein) & $10.51 \pm 3.8$ & $14.73 \pm 0.7^{*}$ & $12.78 \pm 1.5^{\#}$ \\
\hline GSH activity (UM) & $4.03 \pm 0.28$ & $3.52 \pm 0.32^{*}$ & $4.02 \pm 0.44^{\#}$ \\
\hline
\end{tabular}

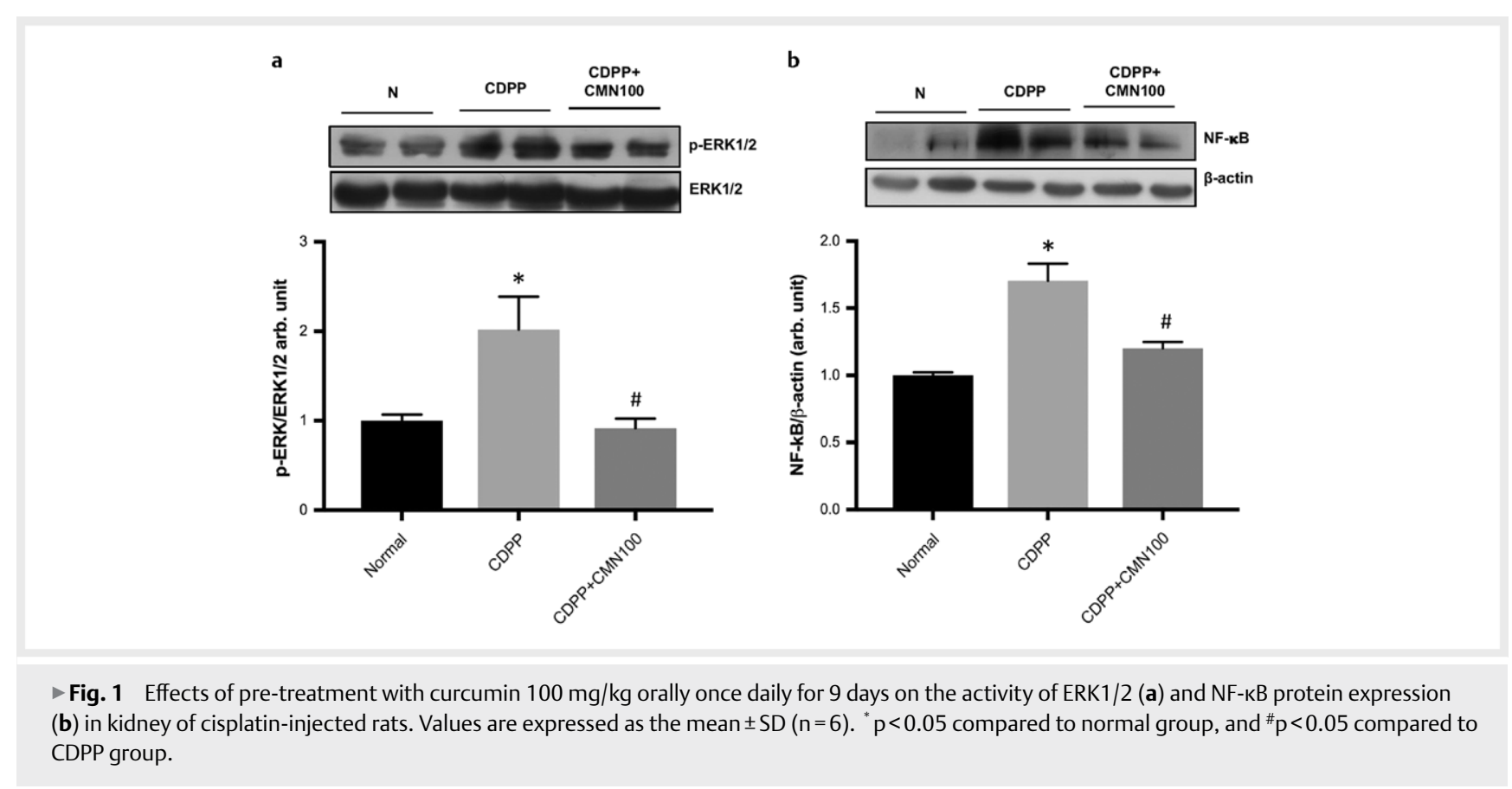

\section{Effect of curcumin on apoptotic and inflammatory markers}

Cisplatin administration caused an inflammatory response as demonstrated by a 1.7-fold increase of kidney NF-kB protein expression ( Fig. 1b), a 5.9-fold and a 6.3-fold increase of TNF- $\alpha$ and IL-6, respectively ( $\triangleright$ Fig. 2a and b) as compared to normal group. Pretreatment with curcumin at $100 \mathrm{mg} / \mathrm{kg}$ dose significantly decreased the protein expression of NF-kB by $29 \%$, and decreased the levels of TNF- $\alpha$ and IL- 6 by $44 \%$ and $29 \%$, respectively. To further investigate whether curcumin has protective activity against cisplatininduced inflammation, we evaluate IL-10 gene expression, a potent anti-inflammatory cytokine. Cisplatin administration significantly reduced gene expression of IL-10 by $25 \%$ as compared to that of normal group. Interestingly, IL-10 levels were significantly increased in curcumin pre-treated group by 7.7-fold when compared to cisplatin-treated group ( $\triangleright \mathbf{F i g} \mathbf{2} \mathbf{2 c}$ ). The apoptotic process was analyzed by detecting the gene expression of apoptotic markers Bax and $\mathrm{BCl}-2$. As shown in $\mathbf{F i g}$. 2d, cisplatin administration induced a 1.9-fold increase in Bax/Bcl-2 ratio when compared to normal group. The Bax/Bcl-2 ratio was significantly reduced in curcumin pre-treated group by $58 \%$ as compared to that of cisplatin-treated group.

\section{Effect of curcumin on NGAL, KIM-1 and histopathological changes}

To evaluate cisplatin-induced renal damage, we performed NGAL, KIM-1 and histopathological analysis. Fig. $3 \mathbf{a}$ and $\mathbf{b}$ illustrates that cisplatin injection induced a 3.5-fold and a 6-fold increase in NGAL and KIM-1 mRNA expression, respectively, early markers for assessment of acute kidney injury, significantly when compared to the normal group. Interestingly, the mRNA expression of NGAL and $\mathrm{KIM}-1$ was reduced in curcumin pre-treated group by $43.8 \%$ and $36.4 \%$ as compared to that of cisplatin-treated group, respectively. Kidney histopathological alterations were shown in $>$ Fig. 4 and - Table 3. In line with progression of renal damage, cisplatin injection induced degenerative change and necrosis in the tubules with infiltration of mononuclear cells in between of tubules. Interestingly, pre-treatment with curcumin ameliorated the pathological changes induced by cisplatin injection.

\section{Effect of curcumin on Ctr1 and OCT2 gene expression assessed by RT-PCR}

To determine the effect of curcumin on renal drug transporters, we performed Ctr1 and OCT2 mRNA expression analysis. As shown in - Fig. 3c, cisplatin injection increased the mRNA expression of Ctr1 by 3.9-fold significantly as compared to that of normal group; this 

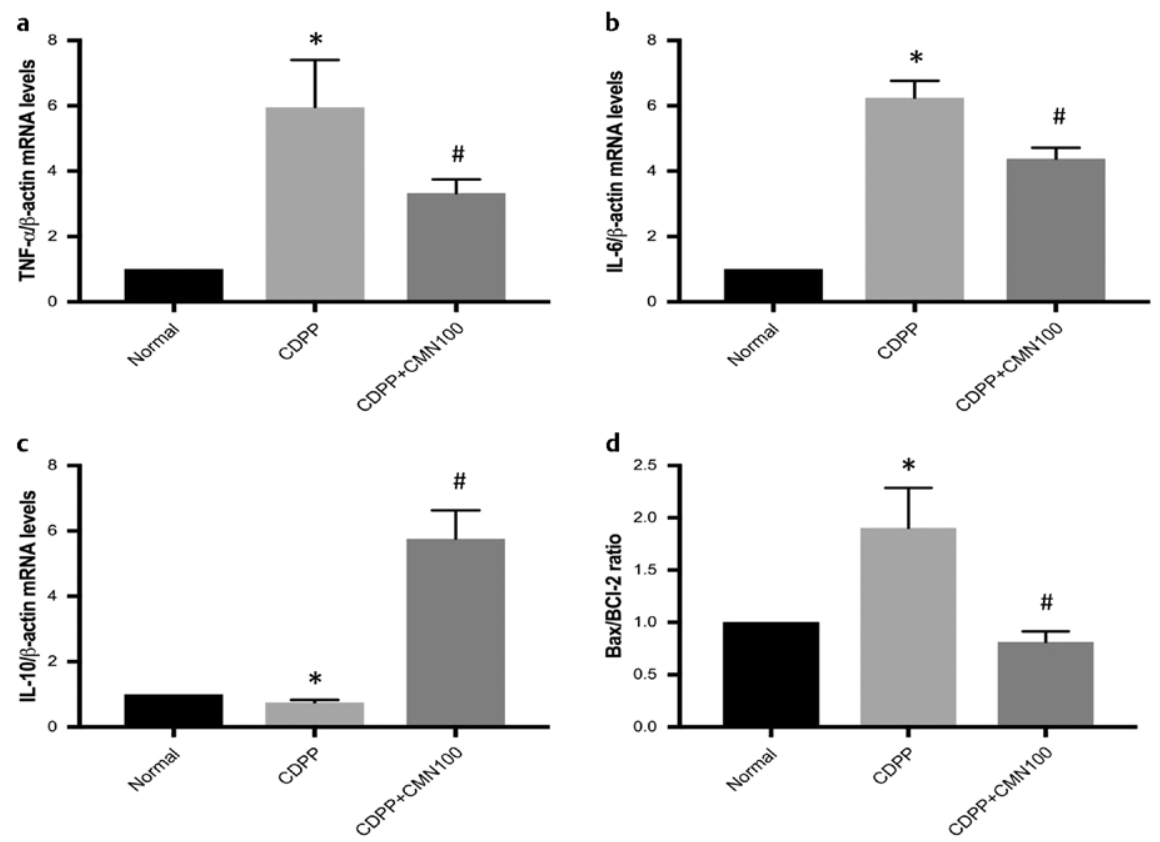

Fig. 2 Effects of pre-treatment with curcumin $100 \mathrm{mg} / \mathrm{kg}$ orally once daily for 9 days on the mRNA levels of TNF- $\alpha$ (a), IL-6 (b), IL-10 (c), and Bax/ $\mathrm{BCl}-2$ ratio $(\mathbf{d})$ in kidney of cisplatin-injected rats. Values are expressed as the mean $\pm \mathrm{SD}(\mathrm{n}=6)$. ${ }^{*} \mathrm{p}<0.05$ compared to normal group, and ${ }^{\#} \mathrm{p}<0.05$ compared to CDPP group.
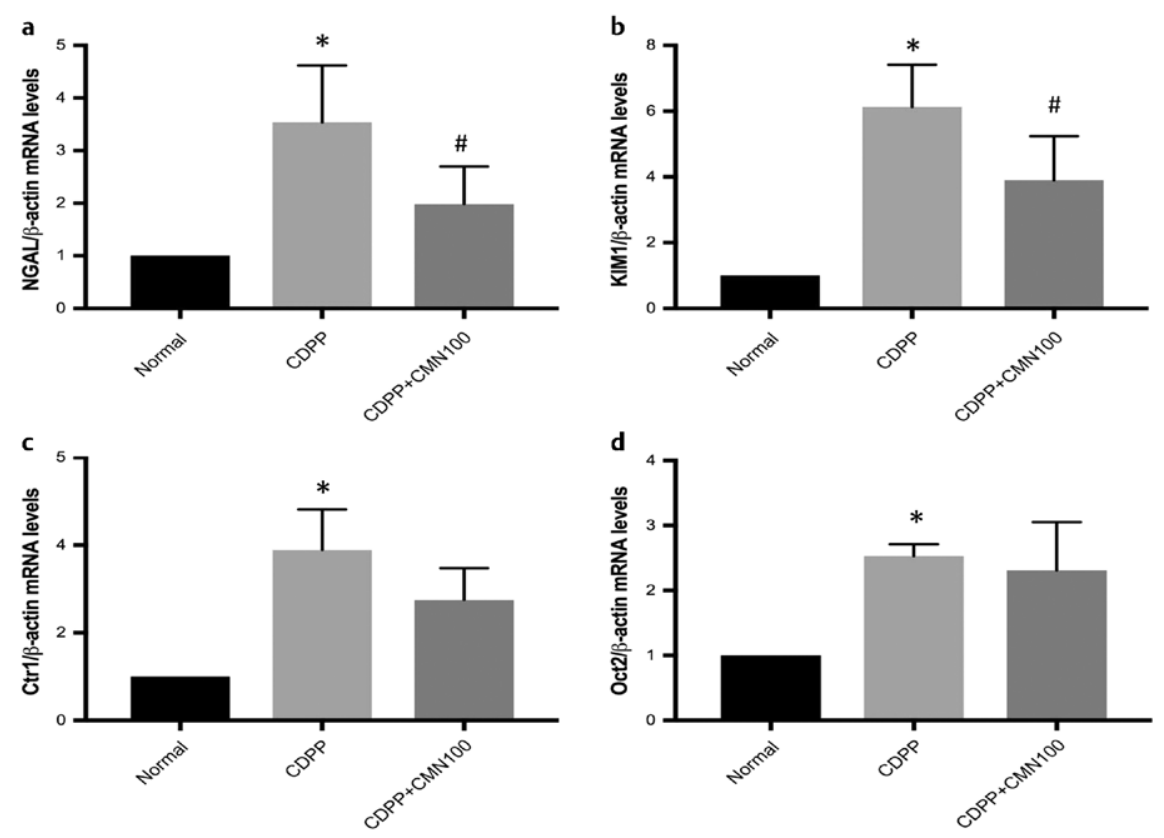

Fig. 3 Effects of pre-treatment with curcumin $100 \mathrm{mg} / \mathrm{kg}$ orally once daily for 9 days on the mRNA levels of NGAL (a), the mRNA levels of KIM-1 (b), $\operatorname{Ctr} 1$ (c), and OCT-2 (d) in kidney of cisplatin-injected rats. Values are expressed as the mean \pm SD $(n=6)$. ${ }^{*}<<0.05$ compared to normal group, and $\#<0.05$ compared to CDPP group. 

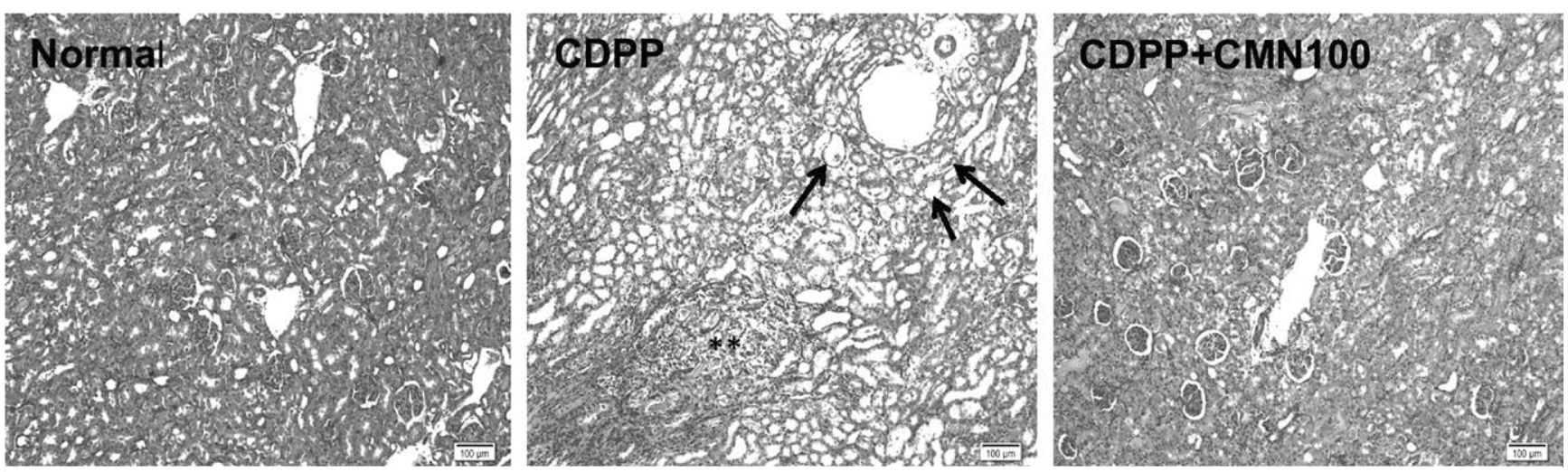

- Fig. 4 Representative photomicrographs of sections from kidney tissues stained by hematoxylin and eosin (x 100 magnification). (Normal) Normal rats receiving $0.5 \%$ CMC-Na vehicle showed normal histology structure of the kidney tubules. (CDPP) Kidney section of a cisplatin (7 mg/kg, i.p.)-treated rats showing necrosis of the tubules (arrows) and infiltration of mononuclear cells $\left({ }^{*} *\right)$. (CDPP+ CMN100) Kidney section of a curcumin $(100 \mathrm{mg} / \mathrm{kg})$-treated rats showing an almost normal morphology.

- Table 3 Histopathological changes in kidney specimens.

\begin{tabular}{|l|c|c|c|}
\hline $\begin{array}{l}\text { Histopathological } \\
\text { alteration }\end{array}$ & Normal & CDDP & $\begin{array}{l}\text { CDDP+ } \\
\text { CMN100 }\end{array}$ \\
\hline- Necrosis & - & +++ & + \\
\hline $\begin{array}{l}- \text { Infiltration of } \\
\text { mononuclear cells }\end{array}$ & - & +++ & + \\
\hline \multicolumn{2}{|l|}{++ Severe; ++ Moderate; + Mild; -Nil } \\
\hline
\end{tabular}

increase was attenuated by pre-treatment with curcumin though no significant difference was seen. Similarly, cisplatin injection increased the mRNA expression of OCT2 by 2.5 -fold significantly as compared to that of normal group, and again this increase was attenuated by pre-treatment with curcumin; no significant difference was seen ( Fig. $\mathbf{3 d}$ ).

\section{Discussion}

Ample of evidence have identified that kidney damage is one of the cisplatin's major dose-limiting side effects [1, 2, 4]. Initially, cisplatin may reduce glutathione (GSH) in kidney tissues contribute to increased generation of reactive oxygen species (ROS) and lead to oxidative stress [1, 2]. Indeed, cisplatin not only causes oxidative stress but also inflicts inflammation in the tubular kidney along with associated apoptosis and anomalies in kidney structure and function. Cisplatin-induced excessive generation of ROS attacks endogenous cellular targets including DNA, lipids, proteins, and stimulates several signaling pathways, namely MAPKs and NF-KB which subsequently exacerbate its apoptosis and inflammation processes $[4,5]$. Curcumin has been shown to have antioxidant and antiinflammatory effects [15]. In the present study, we have demonstrated the kidney protective effects of curcumin against cisplatininduced kidney damage. This is attributable to its ability to elevate antioxidants, attenuate cisplatin-induced increased phosphorylation of ERK1/2, and decrease the inflammation and apoptosis in the kidney associated with significant improvement in renal function and histological analysis.
Previous studies have demonstrated that cisplatin given intraperitoneally in a single dose of $7 \mathrm{mg} / \mathrm{kg}$ induced significant increased of nephrotoxicity markers, such as increased of plasma creatinine and BUN and decreased of creatinine clearance $[9,15,16]$. Similar to previous studies, we shown here, that cisplatin injection to rats at a dose of $7 \mathrm{mg} / \mathrm{kg}$ induced significant increased in the markers of renal function, including plasma creatinine and plasma BUN, and significant decreased in creatinine clearance. Interestingly, renal function was significantly improved by pre-treatment with curcumin. This was demonstrated by improvement in plasma creatinine, BUN, and creatinine clearance.

Inside the tubular cells, cisplatin induces mitochondrial dysfunction and increases ROS production, depletion of antioxidant systems (GSH), and stimulation of renal accumulation of lipid peroxidation products (MDA) $[17,18]$. In the present study, cisplatin injection induced oxidative stress shown by increased of MDA and depletion of GSH levels in kidney tissues compared to that of normal group. Curcumin administration alleviated oxidative stress and improved the antioxidant status. These findings were in line with other studies that showed that curcumin, a powerful anti-oxidant, has protective effects against cisplatin-induced oxidative stress $[7,8,17]$.

OCT-2 and Ctr1 are significant drug transporters in cisplatin penetration and cytotoxicity that are located mainly in the basolateral side of proximal tubules of kidneys and affect the cisplatin accumulation in the kidneys $[19,20]$. Previous studies have shown that OCT-2 and Ctr 1 expression were upregulated by cisplatin and contributed to the drug uptake in renal tubular cells [19-21]. Pabla et al., [20] shown that $\mathrm{Ctr} 1$ knockdown using siRNA approach reduced cisplatin uptake in renal tubules. In vitro study also showed that cimetidine, a pharmacological inhibitor of OCT2, inhibited cisplatin uptake [22]. In line with the previous study, we also demonstrated that OCT-2 and Ctr1 expression in kidney tissue were increased after cisplatin injection and to our surprise, were decreased by pre-treatment with curcumin, though the differences were not statistically significant. Our results were in line to the results of Ulu et al. [19] that have shown that curcumin has the potential of preventing cisplatin-induced nephrotoxicity via the modulation of OCTs expression in the kidney. 
MAPK are a family of structurally related serine/threonine kinase enzymes. Previous studies have reported that ERK1/2, one of the MAPK families signal transduction pathway plays a critical mediator in mediating cellular inflammatory response and apoptosis against cisplatin-induced kidney damage [23-25]. Cisplatin-induced generation of ROS play an important role in activation of ERK1/2, which in turn, phosphorylate numerous different intracellular targets including transcription factors, membrane transporters, and other protein kinases that govern apoptosis and cell death [26-28]. During apoptosis, Bax expression, a pro-apoptotic protein, is increased and inhibition of ERK pathway decreased Bax expression [29, 30].

In the present study, we revealed the ability of cisplatin to induce the phosphorylation of ERK $1 / 2$ in kidney tissues that is in accordance with previous reports [25, 31]. Moreover, cisplatin administration induced elevation of $\mathrm{Bax} / \mathrm{Bcl}-2$ ratio. This result similar to those demonstrated by Wada et al. [32] and El-Naga [10] who demonstrated that the ratio of $\mathrm{Bax} / \mathrm{BCl}-2$ protein expression in kidney tissues was increased following cisplatin injection. Indeed, the increase ratio of pro-apoptotic protein, Bax, and anti-apoptotic protein, $\mathrm{Bcl}-2$, determines the potential of cells to apoptotic process [33]. Pre-treatment with curcumin significantly attenuated cisplatin-induced phosphorylation of ERK1/2 and inhibited the elevation of ratio $\mathrm{Bax} / \mathrm{Bcl}-2$ in the tubular kidney, indicating diminished kidney apoptosis. This finding was supported by previous study that showed that curcumin has a potential protective effect against cisplatin-induced apoptosis in renal tubules [34].

We, next explore whether curcumin could also prevent cisplatininduced inflammation in kidney tissues. Cisplatin induces the activation of NF-kB leads to transcription of inflammatory mediators including TNF- $\alpha$ and subsequently induces the expression of other inflammatory cytokines into the kidney tissues [35, 36]. On the other hand, anti-inflammatory cytokine, IL-10, inhibited the induction of TNF- $\alpha$ after cisplatin administration $[36,37]$. In the present study, pre-treatment with curcumin significantly inhibited NF-кB expression, a transcription factor that activates pro-inflammatory cytokines TNF- $\alpha$ and IL- 6 in response to oxidative stress, and restored IL-10 levels, which can be suggested as one of the mechanism for its nephroprotective role in cisplatin-induced nephrotoxicity. The findings were in parallel to the histopathologic results that showed the ability of curcumin to reduce the inflammatory cell infiltration and kidney necrosis ( $>$ Fig.4 and $>$ Table 3 ). These results were in the same line with Ueki et al. [7] and Kuhad et al. [8] who demonstrated that curcumin at a dose of $100 \mathrm{mg} / \mathrm{kg}$ and $60 \mathrm{mg} / \mathrm{kg}$, respectively, inhibited cisplatin-induced renal inflammation in rodents by decreasing the serum and renal concentration of TNF-alpha.

Kidney injury molecule (KIM)-1 and Neutrophil gelatinase-associated lipocalin (NGAL) are some of protein products that might function as novel biomarkers for the initiation phase of acute kidney injury [38, 39]. Sasaki et al. [39] have demonstrated that the expression of KIM-1 increased after cisplatin administration to rats. In line with previous studies, we also demonstrated that the early biomarkers of proximal tubule kidney injury, NGAL and KIM-1were increased by cisplatin treatment. Pre-treatment with curcumin inhibits the increase in kidney tissues both KIM-1 and NGAL. Indeed, blood KIM-1 levels were elevated in the acute kidney injury as well as chronic kidney disease conditions and functions as a sensitive and specific diagnostic and prognostic biomarker for proximal tubule kidney injury [40].

\section{Conclusion}

In summary, findings in this investigation suggested that curcumin might be of significant protection benefit against cisplatin-induced kidney damage. The protective effects of curcumin appear to be due to suppression of inflammation and apoptosis, in addition to oxidative stress through suppression of ERK1/2 phosphorylation and NF-KB expressions.

\section{Acknowledgements}

We thank Vet. Yulvian Sani, PhD, Department of Animal Pathology, Faculty of Medicine, Institute Agriculture Bogor, Indonesia for helping us in the histopathological study.

\section{Conflict of Interest}

The authors declare that they have no conflict of interest.

\section{References}

[1] Pabla N, Dong Z. Cisplatin nephrotoxicity: mechanisms and renoprotective strategies. Kidney Int 2008; 73: 994-1007

[2] Arany I, Safirstein RL. Cisplatin nephrotoxicity. Semin Nephrol 2003; 23: 460-464

[3] Jiang M, Dong Z. Regulation and pathological role of p53 in cisplatin nephrotoxicity. J Pharmacol Exp Ther 2008; 327: 300-307

[4] Kuhlmann MK, Burkhardt G, Köhler H. Insights into potential cellular mechanisms of cisplatin nephrotoxicity and their clinical application. Nephrol Dial Transplant 1997; 12: 2478-2480

[5] Chang L, Karin M. Mammalian MAP kinase signalling cascades. Nature 2001; 410: 37-40

[6] Prasaja Y, Sutandyo N, Andrajati R. Incidence of cisplatin-induced nephrotoxicity and associated factors among cancer patients in Indonesia. Asian Pac J Cancer Prev 2015; 16: 1117-1122

[7] Ueki M, Ueno M, Morishita J et al. Curcumin ameliorates cisplatininduced nephrotoxicity by inhibiting renal inflammation in mice. J Biosci Bioeng 2013; 115: 547-551

[8] Kuhad A, Pilkhwal S, Sharma S et al. Effect of curcumin on inflammation and oxidative stress in cisplatin-induced experimental nephrotoxicity. J Agric Food Chem 2007; 55: 10150-10155

[9] Topcu-Tarladacalisir Y, Sapmaz-Metin M, Karaca T. Curcumin counteracts cisplatin-induced nephrotoxicity by preventing renal tubular cell apoptosis. Ren Fail 2016; 38: 1741-1748

[10] El-Naga RN. Pre-treatment with cardamonin protects against cisplatin-induced nephrotoxicity in rats: Impact on NOX-1, inflammation and apoptosis. Toxicol Appl Pharmacol. 2014; 274: 87-95

[11] Toora BD, Rajagopal G. Measurement of creatinine by Jaffe's reaction - determination of concentration of sodium hydroxide required for maximum color development in standard, urine and protein free filtrate of serum. Indian J Exp Biol 2002; 40: 352-354 
[12] Bazzano T, Restel TI, Porfirio LC et al. Renal biomarkers of male and female Wistar rats (Rattus norvegicus) undergoing renal ischemia and reperfusion. Acta Cir Bras 2015; 30: 277-288

[13] Livak KJ, Schmittgen TD. Analysis of relative gene expression data using real-time quantitative PCR and the 2(-Delta Delta $C(T)$ ) Method. Methods 2001; 25: 402-408

[14] Mohan IK, Khan M, Shobha JC et al. Protection against cisplatininduced nephrotoxicity by Spirulina in rats. Cancer Chemother Pharmacol 2006; 58: 802-808

[15] Kalpana C, Sudheer AR, Rajasekharan KN et al. Comparative effects of curcumin and its synthetic analogue on tissue lipid peroxidation and antioxidant status during nicotine-induced toxicity. Singapore Med J. 2007; 48: 124-130

[16] Ugur S, Ulu R, Dogukan A et al. The renoprotective effect of curcumin in cisplatin-induced nephrotoxicity. Ren Fail 2015; 37: 332-336

[17] Cetin R, Devrim E, Kiliçoğlu B et al. Cisplatin impairs antioxidant system and causes oxidation in rat kidney tissues: possible protective roles of natural antioxidant foods. J Appl Toxicol 2006; 26: 42-46

[18] Agarwal R, Goel SK, Behari JR. Detoxification and antioxidant effects of curcumin in rats experimentally exposed to mercury. J Appl Toxicol 2010; 30: 457-468

[19] Ulu R, Arslan O, Dogukan A et al. Effects of curcumin on anion/cation transporters and multidrug response proteins in cisplatin induced nephrotoxicity. Int J Clin Exp Med 2016; 9: 19623-19633

[20] Pabla N, Murphy RF, Liu K et al. The copper transporter Ctr1 contributes to cisplatin uptake by renal tubular cells during cisplatin nephrotoxicity. Am J Physiol Renal Physiol 2009; 296: F505-F511

[21] Ciarimboli G, Deuster D, Knief A et al. Organic cation transporter 2 mediates cisplatin-induced oto- and nephrotoxicity and is a target for protective interventions. Am J Pathol 2010; 176: 1169-1180

[22] Sprowl JA, van Doorn L, Hu S et al. Conjunctive therapy of cisplatin with the OCT2 inhibitor cimetidine: Influence on antitumor efficacy and systemic clearance. Clin Pharmacol Ther. 2013; 94: 585-592

[23] Arany I, Megyesi JK, Kaneto $\mathrm{H}$ et al. Activation of ERK or inhibition of JNK ameliorates $\mathrm{H}(2) \mathrm{O}(2)$ cytotoxicity in mouse renal proximal tubule cells. Kidney Int 2004; 65: 1231-1239

[24] Kohda Y, Hiramatsu J, Gemba M. Involvement of MEK/ERK pathway in cephaloridine-induced injury in rat renal cortical slices. Toxicol Lett 2003; 143: 185-194

[25] Jo SK, Cho WY, Sung SA et al. MEK inhibitor, U0126, attenuates cisplatin-induced renal injury by decreasing inflammation and apoptosis. Kidney Int 2005; 67: 458-466

[26] Rubinfeld H, Seger R. The ERK cascade: A prototype of MAPK signaling. Mol Biotechnol 2005; 31: 151-174
[27] Raman M, Chen W, Cobb MH. Differential regulation and properties of MAPKs. Oncogene 2007; 26: 3100-3112

[28] Keshet $Y$, Seger $R$. The MAP kinase signaling cascades: A system of hundreds of components regulates a diverse array of physiological functions. Methods Mol Biol 2010; 661: 3-38

[29] Kim YK, Kim HJ, Kwon CH et al. Role of ERK activation in cisplatininduced apoptosis in OK renal epithelial cells. J Appl Toxicol 2005; 25: 374-382

[30] Park BG, Yoo Cl, Kim HT et al. Role of mitogen-activated protein kinases in hydrogen peroxide-induced cell death in osteoblastic cells. Toxicology 2005; 215: 115-125

[31] Omar HA, Mohamed WR, Arab HH et al. Tangeretin alleviates cisplatin-induced acute hepatic injury in rats: Targeting MAPKs and apoptosis. PLoS One 2016; 11: e0151649

[32] Wada Y, lyoda M, Matsumoto K et al. Epidermal growth factor receptor inhibition with erlotinib partially prevents cisplatin-induced nephrotoxicity in rats. PLoS One 2014; 9: e111728

[33] Humanes B, Lazaro A, Camano $S$ et al. Cilastatin protects against cisplatin-induced nephrotoxicity without compromising its anticancer efficiency in rats. Kidney Int 2012; 82: 652-663

[34] Kang KP, Kim DH, Jung Y] et al. Alpha-lipoic acid attenuates cisplatininduced acute kidney injury in mice by suppressing renal inflammation. Nephrol Dial Transplant 2009; 24: 3012-3020

[35] Kim MG, Yang HN, Kim HW et al. IL-10 mediates rosiglitazone-induced kidney protection in cisplatin nephrotoxicity. J Korean Med Sci 2010; 25: 557-563

[36] Deng J, Kohda $\mathrm{Y}, \mathrm{Chiao} \mathrm{H}$ et al. Interleukin-10 inhibits ischemic and cisplatin-induced acute renal injury. Kidney Int 2001; 60: 2118-2128

[37] Ozer JS, Dieterle F, Troth S et al. A panel of urinary biomarkers to monitor reversibility of renal injury and a serum marker with improved potential to assess renal function. Nat Biotechnol 2010; 28: 486-494

[38] Sinha V, Vence LM, Salahudeen AK. Urinary tubular protein-based biomarkers in the rodent model of cisplatin nephrotoxicity: A comparative analysis of serum creatinine, renal histology, and urinary KIM-1, NGAL, and NAG in the initiation, maintenance, and recovery phases of acute kidney injury. J Investig Med 2013; 61: 564-568

[39] Sasaki D, Yamada A, Umeno H et al. Comparison of the course of biomarker changes and kidney injury in a rat model of drug-induced acute kidney injury. Biomarkers 2011; 16: 553-566

[40] Sabbisetti VS, Waikar SS, Antoine D] et al. Blood kidney injury molecule- 1 is a biomarker of acute and chronic kidney injury and predicts progression to ESRD in type I diabetes. J Am Soc Nephrol 2014; 25: 2177-2186 